\title{
Being a First-Generation Migrant Family Student in Finland: Perceptions and experiences of the Educational Journey to Higher Education
}

\author{
Golaleh Makrooni $^{1}$
}

Tampere University, Finland

\begin{abstract}
This research aimed to investigate the situation of first-generation migrant family students (FGMFSs) in higher education in Finland and determined how FGMFSs experience and perceive their educational journey to achieve higher education. The study focused on the factors that support students to be successful in their education. Fifteen first generation students in higher education who belong to migrant families in Finland were surveyed utilizing semi-structured indepth interviews. In this qualitative study, grounded theory (GT) was used to identify emerging latent patterns from data. Three main categories family values, institutional values, and interpersonal relationships were identified to support students to be successful in their education and enter higher education. The results of this study can help educational institutions, educators, and policy makers understand what factors are important in improving educational success for migrant students.
\end{abstract}

Keywords: family values, first generation migrant family students, friendship, grounded theory, higher education, institutional values.

\section{Introduction}

According to the Organisation for Economic Co-operation and Development (OECD) (2018), there were 21.6 million third-country nationals in the European Union (EU) in 2017. Because of war, poverty, corruption, political persecution, oppression, or the desire for a better life in another society, people are migrating and, in some cases, have been forced to migrate. The increasing migration causes challenges for the host countries and their educational systems that they have not previously faced. Many of the countries in the Western world to which immigrants are immigrating have efficient education systems. These education systems have been developed over a long period of time and adapted to meet the needs of the local population. Findings from comparative studies (Malinen, Väisänen, \& Savolainen, 2012; Mangez \& Hilgers, 2012; Marque etal., 2018; OECD, 2010) provide information on the educational status and performance of children not born and raised in the respective country, and on children and students who were born in the country but whose parents or grandparents were immigrants. These results show some differences between the native and immigrant populations in terms of educational attainment and performance. Considering the contribution of the migrant families' children in the further development of the country as workers or entrepreneurs, various aspects of their lives seem worth investigating.

First-generation immigrants in Europe often experience downward mobility. According to an OECD study (2004), the phenomenon of downward mobility of immigrants is mainly attributed to four factors: language barriers, differences in educational attainment, difficulties in the recognition of their certificates, and access to good jobs. Second-generation immigrants - a rapidly growing part of the population in many countries - are significantly better educated than their parents (OECD, 2010). Nevertheless, the educational level of many children in this second-generation population group is not equal to that of the local population.

Some countries are trying to develop the long-term support for the predominantly young secondgeneration migrant population through a range of educational programs, from early childhood education to formal schooling and then to the subsequent transition into the labor market. Due to the fact that the number of migrant families is exponentially increasing throughout the world, especially in Europe, and because of the importance of generating potential successful workforces, education studies in today's world, particularly about migrant-family students, are vital. However, the majority of programs offered to migrant background youth are vocational, thus most follow-up and evaluation studies focus on them and only a few researchers have focused on the conditions, skills, and problems of FGMFSs in higher education. The aim of this study was to examine the perceptions and experiences of FGMFSs in respect to their educational journey to achieve higher education. The study focused on

\footnotetext{
${ }^{1}$ Faculty of Education and Culture, Tampere University, E-mail: golaleh.makrooni@tuni.fi
} 
how they perceived and experienced their education in the host society, and which factors and processes they emphasize and point out in their life story.

\section{First-Generation College Students}

There are interesting findings on different aspects of becoming and being a first-generation college student (FGCS). Most of these studies have been done in the United States. Initially, FGCSs are those whose parents have at a maximum educational level of a high school diploma (Abdul Rahim \& Azman, 2010; Choy, 2001; Nunez \& Cuccaro-Alamin, 1998; Selamat, Taib, Hshim, Mohd-Zaharim, \& Karupiah, 2013; Stephen, Townsend, Markus, \& Phillips, 2012) and have had little or no access to a university education (Choy, 2001; Dumais \& Aaryn, 2010; Horn \& Nunez, 2000; Ishitani, 2003). Socioeconomically, FGCSs generally come from low-income families (Ceja, 2001; Dooley, Payne, \& Rob, 2009; Selamat et al., 2013); therefore, they have a tendency to manifest low aspirations (Abdul Rahim \& Azman, 2010; Saenz, Hurtado, Barrera, Wolf, \& Yeung, 2007; Terenzini, Cabrera, \& Bernal, 2001), so they are more at the risk of dropping out of higher education (Abdul Rahim \& Azman, 2010; Selamat et al., 2013).

Academically, FGCSs have higher attrition rates and are underrepresented in graduation rates at the bachelor, master, and doctoral levels of education (Ecklund, 2013), and they do not complete bachelor or higher degrees (Nunez \& Cuccaro-Alamin, 1998). However, some perform as well as other students academically, which shows their great potential and could provide an opportunity to access higher levels of education if the conditions are favourable for them (Selamat et al., 2013). FGCSs are likely to work more hours per week than their fellow students, stay less connected to campus and university life, and actively maintain the roles and responsibilities connected to family and community (Ecklund, 2013). Fiscal matters (Nunez \& Cuccaro-Alamin, 1998; Thomas \& Quinn, 2007), and their parents' education level (Saenz et al., 2007) often hinder first-generation students from attending universities and have a significant impact on the academic success of FGCSs. One of the most important predictors of persistence in attaining an education among college students is the educational level of their parents (Nunez \& Cuccaro-Alamin, 1998). Moreover, relative to their peers, FGCSs have distinctively lower selfconfidence and less academic preparation prior to arriving at college (Saenz et al., 2007). Despite the difficulties described above and the related experience on the way to graduation, these students visit universities to improve their social and academic status (Abdul Rahim \& Azman, 2010). Nunez and Cuccaro-Alamin (1998) also found that students with parents who have college experience have an advantage over FGCSs because the parents can help their children manage college life, how to register, how to select courses, and how to apply for financial aid.

According to Williams (2009), many studies have considered educational attainment and its positive effects on the tendency toward migration while others have pointed at the negative effects. FGCSs have many problems attaining, continuing, and finishing higher education. For example, they demonstrate lower academic and social integration, lower enrolment rates, lower rates of graduation, and they face governmental, legal, instructional, and financial barriers (Baum \& Flores, 2011; Chen, 2005; Ersoy \& Uysal, 2018; Nunez \& CuccaroAlamin, 1998). Despite these problems, FGCSs tend to attain college degrees more than those who are native (Baum \& Flores, 2011), which shows their ability to attain, continue, and finish higher education if their basic needs, such as financial situation are provided for. As a result, it appears that there is a lot of information and knowledge about the circumstances of FGCSs. However, little is known about their experiences (Quinn, CorneliusWhite, MacGregor, \& Uribe-Zarain, 2019). Furthermore, even less is known about what the FGMFSs have perceived and experienced during their journey to higher education.

\section{Method}

In this context, the students who are in higher education or graduate from university and belong to an immigrant family whose parents did not do so are referred to as FGMFSs. They developed this desire at some point in their development and school career, or because they were encouraged by the outstanding achievements of dedicated teachers, mentors, and friends. FGMFSs have to cope with new situations in an unfamiliar educational system, and many conditions and challenges can complicate their adaptation. In order to understand how to facilitate their integration into school and higher education, the conditions and challenges they have to overcome must be identified and examined. This should benefit both the students concerned and the educational system as well.

This study aimed to identify the specific patterns, actions, and prerequisites that are crucial to the success of FGMFSs in education. Access to higher education is an integral part of improving the lives, opportunities, and possibilities of FGMFSs, which will subsequently affect their well-being and improve their social mobility and success in work and life. Success is a basic general value for people (Schwartz, 1992). Due to the lack of knowledge on this issue, this study investigated the factors and strategies which have supported and promoted the educational performance of the FGMFSs. It questioned how they perceive and experience their educational path to the higher education and aimed at identifying obstacles or patterns of social interaction which should be overcome in order to be successful on this path. 
This qualitative study was conducted based on the grounded theory (GT) approach (Glaser \& Strauss, 1967, Strauss \& Corbin, 1998). GT was also chosen for this target group because it guarantees the greatest possible openness toward the target group. Often, there are prejudices against this particular target group, or the researcher is not knowledgeable enough about the group. GT is a simple way to discover emerging patterns in data which are derived from systematic collection and is analyzed without being constrained by an underlying theoretical frame of reference. In this study, which is part of a doctoral thesis, emerging theory is limited in the domain of understanding the investigated phenomena, and is conceptually extended by the entire doctoral thesis process.

\section{Data Collection}

In order to find the participants for this study, an announcement was sent by the registration office to all students of all levels at the Finnish university (about 14,000 students) to the intranet webpage, the student union Facebook page, and to some faculties at the university. Posters were printed and distributed for the different university faculties and the snowball system was effectively used, which also resulted in data collection from other universities. The detailed announcement and the explanations were intended to satisfy the need for the respondents to understand the purpose of the interview and to demonstrate the trustworthiness of the researcher (Buchanan, Boddy, \& McCalman, 1988).

A total of fifteen FGMFSs (eight females and seven males) from different Finnish universities were interviewed for this study. Most of the participants were from the second largest Finnish university. The participants were from Iran (seven), Iraq (four) and of mostly (eight) Kurdish ethnic origin, four from Africa, one from Russia and one from Vietnam. Although according to Statistics Finland (2018), Iraqi, Syrian, and Russian immigrants respectively with 2369,1422 , and 1420 persons were reported as the three largest group of immigrants in 2017, however, it was not concretely considered to be a factor for reaching the specific common immigrant group for this study. It is evident that the results might be different if the composition of the informants varies. However, in this case it was considered important that there were interviewees from the most common groups immigrated to Finland in 2017. The majority of Kurdish Iranians and Iraqis among participants was due to the use of snowball method. Four of participants had graduated, and the rest were studying various subjects at the master and bachelor levels. One of the participants was born in Finland, and the others had moved to Finland at different ages - from early childhood to adolescence to young adulthood. The 90 to $110 \mathrm{~min}$ interviews were all recorded and transcribed. The English language was used for the interviews.; the mother tongue (Kurdish) was used for three participants. To guarantee that the names of the respondents would remain anonymous, the guidelines of the Finnish Advisory Council on Research Integrity were followed.

One of the essential principles of GT is that no pre-existing hypothesis is attempted to be verified: rather, "a theory should be emerged from empirical data" (Rupsiene \& Pranskuniene, 2010, p. 10). For data collection, questions should be simple and open-ended. Simmons (2010 cited in Holton \& Walsh, 2017, p. 68) called these "grand tour" questions. The questions focused on how the FGMFSs perceived and experienced their education in the new country, from their childhood up to their current position, in respect to their migration background. What emerged during each interview was considered when conducting the next interviews in order to determine the relationship among salient themes; memo writing was used during this information gathering process. Some of the questions asked were as follows: How did you perceive and experience yourself on your educational journey? What is your situation regarding friendship with others, and how does it affect your integration into school and society? How did your family, friends, and teachers perceive you? How did you experience your education in different phases? What helped you to study at university as a student? How did you manage to master the challenges?

In this extensive, semi-structured in-depth interview, personal stories and data were collected. For this purpose, a rough guideline was developed with questions to serve as a framework. The type of questions varied, and more specific questions were asked in the interviews depending on the course of the interview. During data collection, some further questions emerged for the participants about such topics as the role of their mothers, teachers, friendship, their transition process, identity development, and cultural integration. The respondents were asked to relate details about their school days, their teachers, their friends, their relationship with their parents, their relationships with relatives, and episodes which had a lasting influence on their decision to go to university. They were also asked about their values and emotions, as well as the challenges caused by the differences between their country of origin and the host country's cultures. If the participants did not mention the actors and people who influenced them in the first interviews, such as teachers, mentors, friends, etc., they were asked what role such persons played in the success of their training. According to the GT methodology, broad questions were asked at the beginning of the study and each interview was conducted based on the previous interview. This process was repeated several times until no new relevant topics were discovered.

An important question when using GT is from when are enough data collected to achieve theoretical saturation? The numbers of data required for saturation is given as $10-15$ in the corresponding literature and depends also on the degree of complexity of the research project (Aldiabat \& Navenec, 2018). According to Weller et al. (2018, p.18) "in general, probing and prompting during an interview seems to matter more than the number 
of interviews". In this study, theoretical saturation had been achieved after 15 interviews, as no new outstanding concepts or other related data on the case of the study emerged (Holton \& Walsh, 2017; Weller et al., 2018). After the interview 10th, no new key themes were added. However, to ensure that data saturation was achieved, and to avoid early completion of data collection, five more interviews were conducted. The researcher stopped collecting further data after being convinced that the theory has arisen, and the categories were saturated. Continuous memo writing helped researcher to foster the saturation as well.

\section{Data Analysis}

Written transcriptions of the audio files were created as well. The interviews were all transcribed in English. After each interview, interview memos were written. Collecting and analyzing data were done simultaneously by memo writing. Memos were generated constantly according to the GT method as an important iterative process. According to Strauss and Corbin (1994), open coding, axial coding, and selective coding were done. Analysis of the data started with the first step of open coding, for example, one interviewee (see Table 1) mentioned "always my parents told me you should go to university and they wanted me to go to university one day... they encouraged me." The open coding for this example is "motivation from mother," and the axial coding is "encouragement and achievement as a basic human value." Based on these coding and reading and rereading the transcriptions and writing memos to find the patterns that fit to the data, the concepts and categories were identified that were represented in the data. Selective coding as a final step was used to integrate and organize the key categories. Beside the continuously coding process the four steps of the constant comparative method developed by Glaser \& Straus (1967) help that the theory will emerge and the data will be saturated, these are: "1) comparing incidents applicable to each category, 2) integrating categories and their properties, 3) delimiting the theory, and 4) writing the theory" (p. 105). To identify a coherent story, the three main categories were integrated to understand the educational journey of being successful and accessing higher education. For analyzing the data, both manual and technical analyses were conducted using Atlas.ti. Using Atlas.ti to link codes and categories and reading and rereading each interview convinced the researcher of the accuracy of the main categories.

\section{Findings of the Study}

Three categories were found that were related to what FGMFSs perceived and experienced on their way to university: family values, institutional values, and friendships (interpersonal relationships).

\section{Category One: Family Values}

The results of the interviews indicated that family values was one of the selective categories. Through the open coding and, subsequently, the axial coding, the following key categories emerged: encouragement, achievement, motivation, role of the mother, value of education, language broker, children responsibility, role model, and siblings. According to Schwartz (2014), achievement is an important value for personal success. Through achievement, one demonstrates competence in relation to social standards. Achievement is defined in this context as a value that I not only want to achieve for myself, but also as a value that I want to pass on to my children and as an investment. There were many statements about and examples of this. Encouragement (12 times) (Table 1, quotes A2, A6, A10, and A11), often from parents and especially from mothers (6 times) was mentioned by the participants. Some of the parents (mostly mothers) pointed out to their children that they themselves could not be able to learn because of their own circumstances (social and cultural conditions), but they knew from their life experience how important it is to learn. Encouragement was offered to use the opportunities available. Moreover, parental support through emotional motivation and encouragement was repeatedly pointed out. The parents could not help their children with the demands made by the school. However, they supported the children mentally and emotionally. The parents pointed out how important it was to learn and to get a better life and a good job. This supported the concept that the family is generally seen as the most important socialization place in which social learning takes place (Padilla-Walker, 2008).

In the family, the developing child continuously learns new practices and routines. This is part of the family culture. In the long run, these habits develop, as Bourdieu $(1984,1986)$ puts it, into certain behaviors, dispositions, attitudes, and lifestyles of a person. Family cultures, on the other hand, are embedded in a wider cultural and social context. Each family culture can fit more or less well into the surrounding socio-cultural context. Parents invest in their children as the next generation of the family (Coleman, 1988). The next generation will then (hopefully) support the parents later in life. This also includes communication about different life issues, such as discussions about education and professions (Table 1, quote A1), encouragement (Table 1, quote A10), and what they can achieve, such as becoming a doctor (Table 1, quote A6), in their personal life. Fathi (2018) pointed out that research has shown that parental involvement in raising children has an impact on their educational achievement, career path, and educational aspirations. In this process with the parents, however, the children and adolescents are often also actors in the migration process. The children are not only passive recipients of parental culture (Devine, 2009), but they also play an active role when it comes to language and supporting their parents in daily life. Through classroom learning, children are often engaged as language mediators and translators for their 
parents. The role of children as interpreters often leads to misunderstandings between parents and the school. Bauer (2016, p. 1) calls these children "language brokers" and defines this concept as follows: "Language brokering is an activity whereby children interpret and translate for their migrant parents who have not yet learned the language of the new country." This situation was also mentioned several times in the interviews $(n=4)$ (Table 1 , quotes A5 and A13). The children helped with tasks such as translating forms or visiting administration offices. In the interviews, they mentioned that it made them become more mature earlier than other classmates at school, and they had to help their parents very often (Table 1, quote A13). According to the life stories of the FGMFSs in this study, it was concluded that most of their parents did not have adequate linguistic knowledge, which made them dependent on translators and their children when dealing with official matters, such as doctor's appointments, banking, etc. One of the interviewees criticized her parents for not being more assertive in learning the language during the first years after their arrival. The reasons for the parents' passivity was explained by the uncertainness and inexperience in learning a new language, despite had been in Finland for long time, as well as dependency on their children to take care of language issues in the host country.

\section{Table 1.}

Family Values

\begin{tabular}{|c|c|c|c|}
\hline Interview & Quotes & Open coding & Axial coding \\
\hline A2 & $\begin{array}{l}\text { "... always my parents told me you should go to } \\
\text { university, and they wanted me to go to university one } \\
\text { day... they encouraged me. My mother always told } \\
\text { me that I should not make the same mistake that she } \\
\text { did as she did not have the chance to study." }\end{array}$ & $\begin{array}{l}\text { - Motivation from } \\
\text { mother } \\
\text {-Education is } \\
\text { important }\end{array}$ & $\begin{array}{l}\text { - Achievement as a } \\
\text { basic human value } \\
\text {-Value of education } \\
\text { - Role of mother } \\
\text { - Encouragement }\end{array}$ \\
\hline A5 & $\begin{array}{l}\text { "My parents asked for help a lot, but they would never } \\
\text { put their needs before mine, so I got lucky family } \\
\text { wise. If my mom says she needs a translator, if she } \\
\text { takes me, then I am away from school ... If parents do } \\
\text { not understand the importance of school or how much } \\
\text { can be missed or what can happen if you miss school } \\
\text { all the time,... }\end{array}$ & $\begin{array}{l}\text { - Helping parents } \\
\text {-Being an } \\
\text { interpreter } \\
\text {-Understanding } \\
\text { school } \\
\text { - Expectation in } \\
\text { the family }\end{array}$ & $\begin{array}{l}\text {-Value of education } \\
\text { - Language broker } \\
\text { - Support of parents }\end{array}$ \\
\hline A6 & $\begin{array}{l}\text { "... my mother wanted me to be a doctor ... She } \\
\text { always motivated me for everything, she is amazing } \\
\text {.." }\end{array}$ & $\begin{array}{l}\text {-Motivation from } \\
\text { mother } \\
\text {-Value of } \\
\text { education }\end{array}$ & $\begin{array}{l}\text { - Role of mother } \\
\text { - Encouragement }\end{array}$ \\
\hline A10 & $\begin{array}{l}\text { "To be honest, someone that always encouraged me } \\
\text { to study and gave me the feeling that studying is good, } \\
\text { and that I should study after my vocational school, } \\
\text { was just my mother. It is true that she is not literate } \\
\text { enough, but always she liked that I studied." }\end{array}$ & $\begin{array}{l}\text {-Motivation and } \\
\text { encouragement } \\
\text { from mother } \\
\text {-Importance of } \\
\text { education }\end{array}$ & $\begin{array}{l}\text {-Achievement } \\
\text { - Encouragement } \\
\text { - Mother's role } \\
\text {-Value of education }\end{array}$ \\
\hline A11 & $\begin{array}{l}\text { "... my mom has a big influence on me, she was } \\
\text { always encouraging me. She told me that your } \\
\text { education as a woman is a freedom passport, those } \\
\text { were always her words. She was telling me to } \\
\text { continue, 'I am proud of you,' this made me proud to } \\
\text { continue. There is no boundary for your dreams for } \\
\text { your education ..." }\end{array}$ & $\begin{array}{l}\text {-Motivation, } \\
\text { encouragement } \\
\text { from mother } \\
\text {-Getting a vision } \\
\text { for the future from } \\
\text { mother }\end{array}$ & $\begin{array}{l}\text { - Motivation } \\
\text { - Encouragement } \\
\text { - Mother's role } \\
\text { - Achievement } \\
\text { - Value of education }\end{array}$ \\
\hline A13 & $\begin{array}{l}\text { "Language still is a barrier for my parents because } \\
\text { Finnish language is a difficult language. ... the kids } \\
\text { learn it much easier and faster and actually you } \\
\text { become an interpreter for your family and do all the } \\
\text { stuff, ... you become adult when you are a child and } \\
\text { your parents became kids because you are trying to } \\
\text { take care of them. ... you become responsible. I think } \\
\text { it affected me to be mature very early when I could } \\
\text { have stayed a little child little bit longer." }\end{array}$ & $\begin{array}{l}\text { - Language barrier } \\
\text { for parents } \\
\text { - Become } \\
\text { interpreter } \\
\text { - Expectation in } \\
\text { family } \\
\text { - Changing one`s } \\
\text { role } \\
\text { - Responsibility } \\
\text { - To become } \\
\text { mature early }\end{array}$ & $\begin{array}{l}\text { - Language broker } \\
\text { - Family culture } \\
\text {-Family migrant } \\
\text { education(language) } \\
\text {-Collectivistic culture }\end{array}$ \\
\hline
\end{tabular}




\section{Category Two: Institutional Values}

Through the axial coding, some of the key categories emerged: equality policy, equity, culture of trust and respect, teachers and support, teacher encouragement, teacher and identity agent, teacher-student interaction, school and home interactions, and flexibility in educational institutions. Consequently, institutional values was identified as another selective category.

The results of the interviews reflect, apart from a few statements, that the students perceived and experienced values, such as equity and respect, in the Finnish institutions through teachers and staff in most cases. Respect was shown by the teacher for the students when referring to their abilities and their personalities (Table 2, quotes A11 and A15). Overall, the teachers were mainly judged to be helpful and fair. The students mentioned that the teacher motivated and supported them. The most important support was provided by teachers who had a strong and continuous influence on students' identities and attitudes (Table 2, quotes A6, A9, A11, A12, and A131). The teacher's understanding and the way these students acted and behaved made these students motivated and optimistic to believe in their abilities and their future in Finland. This support also took place in respect to the teaching methods used. They ensured that the students were often in a group with other Finns and that no groups were formed with only foreign students (Table 2, quote A12). Equity was perceived and experienced in the classroom in two ways. One was the positive aspect of equity which showed no difference in the way someone was treated by the teachers; they treated every student the same (Table 1, quote A7). The second was the negative aspect of equity which was caused by stress because the expectations were the same for everyone. Moreover, language problems caused stress regarding the participants' study and assessment (Table 2, quote A10). From the participants two have studied at the same time in secondary and vocational school. The other participants studied in high school and three attended vocational school because of the age of their arrival in Finland and the language difficulties they had. In two interviews (Table 2, quotes A2 and A13-2), the interviewees also mentioned discussions with the institutions and the teachers about their future school careers if they continued their studies in vocational or high school. However, although these pupils were interested in continuing their studies in high school, teachers and consulters tried to guide them to the vocational school. The participants explained it from two perspectives. First, students assumed that teachers wanted to prevent their failure because of their own perception of the skills and Finnish language competence of students, as high school with focus on theoretical subjects is more difficult than vocational school, which focuses more on the occupation and practice. Secondly, they assumed that teachers might consciously guide them to vocational school. Ultimately, the students in these cases asserted themselves, and agreements were made with the teachers for them to be able to go to high school.

The Finnish school system is open and flexible. Flexibility means that students can continue their education in any age, even after taking breaks from it. This organizational structure can also be seen as a sign of equality. In one interview (Table 2, quote A10), there was a critical comment of the teacher's assessment considering the equality of treatment in the case of language challenges such as those experienced by non-native speakers. In addition, students, especially in higher education, perceived that the reason for this behavior of teachers in relation to language was due to an assumption. Teachers assumed, they felt, that someone who has been accepted to university has the same level of language proficiency as the local students. Obviously, the teachers' perception was not in line with the students' perception of their abilities, interests, and especially their language skills. On the other hand, it was noticeable that language skills depended on the age of arrival of the FGMFSs in Finland. If a child of migrant parents was born in Finland or moved to Finland at any early age, he or she would probably not have a language problem. Also, such students would have greater social capital in the form of social relationships as opposed to FGMFSs who migrated later in their lives (from 11 to 18 years of age). The school and the university as institutions were judged to be equal in their organization. This equity was recognized as a high value in the host country and very often seen as a clear contrast to the country of origin. However, this meant based on the interviews that some students worked harder and were more stressed than others as well.

Table 2.

Institutional Values

\begin{tabular}{|c|c|c|c|}
\hline Interview & Quotes & Open coding & Axial coding \\
\hline A2 & $\begin{array}{l}\text { "... when I was at secondary school. ... My grades were } \\
\text { not good because I did not have any motivation to study. } \\
\ldots \text { my teacher always said to me do not go to high school, } \\
\text { go to the vocational school, because it's better for you. I do } \\
\text { not know why she told me that, ... maybe she did not } \\
\text { believe that I could go to high school ... she wanted to } \\
\text { make it shorter for me like after that I can get a job and be } \\
\text { like a nurse. I do not know maybe she knew better than } \\
\text { me." }\end{array}$ & $\begin{array}{l}\text {-Grades have not been } \\
\text { good } \\
\text {-No motivation to study } \\
\text {-Teacher told her not to } \\
\text { go to high school } \\
\text {-Not sure why this } \\
\text { option should be the best } \\
\text {-Vocational school } \\
\text { advised }\end{array}$ & $\begin{array}{l}\text {-Different } \\
\text { perceptions on the } \\
\text { abilities } \\
\text {-Equity/ } \\
\text { discrimination } \\
\text { - Uncertainty } \\
\text {-No encouragement }\end{array}$ \\
\hline A5 & $\begin{array}{l}\text { "... I have really nice teachers. Of course, you cannot } \\
\text { always get along with all of your teachers, } \\
\text { I always had like a good relationship with my }\end{array}$ & $\begin{array}{l}\text {-Relationship between } \\
\text { teachers and students } \\
\text { - Good teachers } \\
\text {-Modeling for the future }\end{array}$ & $\begin{array}{l}\text {-Student teacher } \\
\text { relationship } \\
\text { - Role model }\end{array}$ \\
\hline
\end{tabular}


-Teachers as an identity agent too." “... From 7 to $9 \mathrm{I}$ had a teacher who motivated me as much as my mother ... She had meetings with my mother at least ten times that I did not know about, telling my mother that he has potential abilities ... and actually because of her I went to high school and she made me to go to high school."

"My teachers did not treat me in any especial way ... treated me as an equal, and they did not treat me bad nor try to especially help me. Teachers treated me good not because I was a foreigner, but because I was a good student ... For those of us who had not been good in everything or something, then teachers helped them more in case of Finnish language if they did not understand some of the concepts."

"My teachers were so good and helped me ... I remember ... teachers divided the book for me and told me that you can read these pages not all of them as these subjects have a lot of contexts in Finnish, and also their behavior was so good to me."

"In my vocational school, teachers do not pay attention that you do not know the language as Finnish students. ... They should consider that our language is not as good as other Finns, and it is difficult for us and pay attention to this when they are grading. They do not give you a feeling that you are a little bit different from other Finns, ... you could not see yourself different, but it has also a negative aspect. The negative aspect is that you always in stress. It could be equity from their view point, but equity could be considered when my mother tongue also is Finnish, but I am not such a person in a same level with other Finns."

“... School made me love the subjects, and there was respect for the students, respect, the teacher was respecting us ... you felt like you are important... my teacher ... she was an angel ... when I entered the high she made me what I am, I mean she made me totally love chemistry with everything".

“... teachers especially who are in vocational school motivated me a lot ... I remember they were always, you know, supporting me... they were talking, walking, and telling me what to do ... They know that there are these language issues ... and they always made sure that, if it is about group work, there is someone who is with me so I was not staying alone, ..."

A13-1 "I think some teachers encouraged me, not all the teachers, because I spoke very good Finnish and I was like Finnish students, but I knew Arabic. It was a very good combination, and they tried to push me and other students told me like you are going to be a very much needed person in the future."

A13-2 “... when I was in the middle school, I was ... a good student ... I wanted to go to high school. ... when I was in 9th grade, one teacher who said to me, 'Are you sure you want to go to high school ... Finnish is not your first language?' at that moment, I was like you do not say that to me because it is like my first language she said, 'Yes, but it's going to be hard,' and I was like, no I am good and will apply for high school, and I did not have any idea to go to vocational school. They think because you have an
- Meetings between teachers and parents - Teacher gives positive feedback

- Being responsible

- Positive influence

- Similar treatment according to performance - Support from teachers

- Help from teachers - Good behavior of the teacher

-Different perception on equity for teachers and FGMFSs

-Positive aspect of equity: no differences - Negative aspects of equity: stress subject

- teacher influence

- Respect

- Teacher and identity of FGMFSs

-Vocational school teachers were supportive -Teacher responsibility and taking care

-Relationship between teachers and students

- Motivation

-Teacher`s encouragement

- Encouraged by other students

\section{- Good student}

- Teacher perception different on language -Vocational school advised -Different perception on FGMFSs' ability and their strength
- Evaluation

- Encouragement
- Family and school relation

-Encouragement

- Equity

- Role of mother

- Equity

- Support from teachers

- Support

- Equity

- Perception of value by teachers and FGMFSs - Equity from two lenses 
extra language it's a barrier for you and gets hard for you ..."

"When I got good grade and I could handle my courses at university, it made my classmates (Finnish) wonder, and they thought like how she can make it as a foreigner. But it is not like that in view point of my teacher. Each time when this teacher saw me, he mentioned this sentence ... "I put away my hat for you", it means I respect you, you are a

- FGMFSs' ability

- Motivation

- Positive feedback from

teacher

- Respect from teacher
- Respect

-Encouragement

- Teacher's role

foreigner, but you have a lot of motivation and put much effort to do your studies.

\section{Category Three: Friendship (Interpersonal Relationships)}

Through the open and then axial coding, some of the following key words emerged: challenges in friendship, cultural barriers and friendship, friendship meaning, role model, friend and integration, academic performance and friendship, language, collectivism, and individualism. Therefore, friendship (interpersonal relationship) emerged as a third selective category. The interviews conducted in the course of this study pointed out the importance of having friends as a significant factor, not only for academic support but also for cultural and social integration. Moreover, the participants saw friends as a way to enhance their language skills, as well as the way they think, study, and work, too. The results in terms of friendship were very different. In general, friendship was considered very important and desirable, but the fulfillment and implementation of this wish was expressed as being very difficult for some. Bourdieu (1984) described this as access to social capital. Some had friends from school, and they got motivation and support from them; for them, it was always easy to find friends whenever necessary, no matter where they lived (Table 3, quotes A2, A10, and A14). Some explained that it was very difficult to find friends, particularly in high school, because of the course-based system, and others already had friends from hobbies or outside of school (Table 3, quote A12). On the one hand, some attributed this to the values and behaviors of the Finns, and they felt that Finns are introvert (Table3, quote A9). On the other hand, they saw their migration background as the reason. For some, it was also a stress not to make any friends (Table 3, quote A1). Some could not keep up contact with colleagues or classmates outside of university or work, and the friendship was limited to those places (Table 3, quotes A9 and A15). Another had friends (Table 3, quote A10), but did not share the same values with them, and pointed out that there were differences concerning behavior and humor based on cultural differences.

Table 3.

Friendship (Interpersonal Relationship)

\begin{tabular}{llll}
\hline Interview & \multicolumn{1}{c}{ Quotes } & Open coding & Axial coding \\
\hline A1 & "First of all, I felt a lot of shame like ashamed & - Feeling shame & -Friendship \\
& of myself because I had moved from ... and I & and stress in & means stress \\
& thought people like judge me because of & contacting people & -Perception of \\
& (migration) this and ... well, in general, even & -Perception of & himself as a \\
& though I made an effort to forget about this, I & himself as a & foreigner \\
& still felt like very inadequate. ... and always I & foreigner &
\end{tabular}
felt like stressful, and it was unpleasant."

"I think my friends motivated me, because I had my friends all in Finnish, they were from good families ..., and they all wanted to go to the university, so I think it was the biggest motivation for me as I wanted to be like them."

"I do not have a lot of Finnish friends; I just have my old colleagues that sometimes I meet rarely. I think Finnish are people that are so introverted, and they are in among themselves. Getting friends among Finnish is so hard for me ... we are so close when we are at work and ... but our relation and connection is just at work environment not outside our workplace."

“... at school I have some Finnish friends. All my classmates are my friends ... we are going outside for lunch. I get help from ... we are friends but ... still we have cultural
- Friends motivate him - Friends wanted to go to university

- Hard to get

friends

- Friends from

work

- No close friends

- Perception of

Finns as introverted

- Having Finnish

friends
- Role model
- Motivation

- Perception of friendship is

different

- Friendship and culture

- Friendship and

culture

- Humor 
differences. ... They laugh at something that is not funny to me, and I could not laugh. I have tried to be integrated, but as I told you, I could not lie and laugh at something that it is not funny to me and I cannot just laugh as they laugh."

A12 "I had friends, but they were not from high school and mostly in vocational school, and the friends that I had liked were from outside school ... like from somewhere else, like from playing football and something like that. I think it was really hard to get to know Finns ...

A14 "For me it is easy to get Finnish friends ... I still have friends that I knew form the age of five that are my best friends ... I got to know them when I was five. They are my best friends. ... it affected my integration. ... They give me another view of life. I always thought I am going to be at the same level with boys, girls, and everyone.

A15 “...To be honest, to be friends with Finnish is not easy. When I studied in university, generally, I had a good relationship with Finnish students, and I asked them (for) help and they really helped me. But our friendship was just about our study inside the university, and it did not go further like to be with them outside the university. I have to say that the system here is based on the courses, and you just go to the course and come back, so it is not like a place that helps you to make friendship deeper."
- Cultural

differences in

friendship

- Different kinds of

humor

-Friends from outside of high school

\section{- Hard to get \\ friends from high school}

- Friendship and age of arrival - Integration and learning from friends - Adjusting with friends, hope

-Getting help from friends

- Friendship limited to inside university -No close friendship
- Support

-Friendship and institution

\author{
- Friendship and \\ integration \\ - Friendship and \\ modeling
} -Friendship and institution

\section{Discussion}

In this study, fifteen FGMFSs aged 20-30 shared their experiences and perceptions on their way to university, their transition to it, and being at the university. Using and following the steps of GT, three main categories for this study emerged: family values, institutional values, and friendship. These categories have been perceived and experienced by the participants, they have played a significant role in their breaking through certain social patterns and moving on successfully, entering higher education institutions, and finding their way in the Finnish host society. These categories help to understand what is happening during this journey and where further activities of the host country are necessary to support more students to pursue an academic career. The linkage among these three categories is explained by openness and being open-minded. Openness emerged as a core category which describes the latent pattern of this data-driven study.

Family values describe the attitudes, ideas, and beliefs which a person inherits from his or her parents. The cultural imprint of the family affects the family structure, family culture, and the hierarchy within the family; thus, it affects the self-image of how one positions oneself within a society. An essential imprint in all cultures within a family or within a society is to be successful. Success can be divided into material success (earning a lot of money, building a house), ethical success (i.e., I'm always honest, I do not get offended), religious success (i.e., I will not reject my religion, I follow the instructions inherent in my religion) or cognitive success (I want to study).

One factor in the family, the encouragement and support of parents, especially mothers, is what appears to play an important role in adolescence. In this study, although some mothers had not even attended school, they always encouraged their children to continue learning and succeed at school. The encouragement and emotional support from mothers was mentioned by 8 of the 15 participants, which strongly identified the importance of their mother's encouragement and emotional support during their children's study at schools, even in higher education. They compared the situation in their origin countries with the new opportunities in the host society, and they acted consciously to help their children to be successful and take the opportunities offered in the host society. The 
perception of inequality in education, especially for women, in their countries of origin compared with the host society also played an important role. The role of father and even grandfather also emerged from the data, which showed how they took care of their children's schooling and academic career. However, one negative aspect of parental involvement was that some parents used their children as translators or language brokers (see Table 1). Here, we see deeply-rooted expectations also coming from their culture, that children fulfill certain duties. These situations are seen both positively and negatively. On the positive side, the children felt more responsible and liked being helpful; but, they experienced it negatively as they could not have the same type of childhood as other classmates had. Being aware of this stressful situation for migrant children could lead to the development of activities that help and support them.

Overall, learning and education had a consistently high value in the families of the interviews. Education was validated by the family, and it was transferred to the children to appreciate education and set a goal for their life. Setting goals worked as a valuable dynamic for them to continue and not give up reaching them. This shows that the value of education based on family values is considered an instrument for upward mobility and enhancing one's social status. It is rooted in the families as a value to achieve success and emphasizes the belief in the power of education. The results presented here also agree with the findings of Schwartz (1992, 2014). For him, success represents an important value in the family. Here, we see families who believe in educational success for their children. They, themselves, can later benefit from this success, or focus on this success only for their children. These family values are thus transferred to the children.

Schools and universities are important institutions and are of great value in Western democracies. Yet, the school systems are inherently shaped by the behavior and reputation of teachers. This study found that all respondents considered school an important place where equality and justice exist. According to Mäkinen (2013, p. 1), "the Finnish education system combines high performance with widespread equality, justice and individual classroom support." This was very strongly perceived and mentioned by the interviewees. Educational institutions were seen as resources that support and help them develop their own skills and their hope for a better future. They recognized the expanded opportunities they would gain with education. What was appreciated by the FGMFSs at school and university, and the focus of all the interviews, was the role of the teachers and the quality of interaction with them and, in some cases, with their parents. The value of equality was also evident in all the interviews. However, equity without the teachers' consideration and efforts did not appear to be very influential. They appreciated the role of the teachers, who had a strong influence on them, more than the emphasis on equality. It turned out that they felt that educational institutions view and respect all students in the same way without regard to their personal and cultural backgrounds. However, FGMFSs often do not have the same cultural and pedagogical background that other Finnish students bring from home. Most participants also identified language and cultural barriers as very significant. For example, the difficulty of asking questions was mentioned. At the same time, they emphasized the interaction with teachers who ask questions, encourage them to ask, and not to be shy but confident. They also indicated that language difficulties often lead FGMFSs to vocational school or to subjects such as mathematics and physics. In these subjects, according to the interviewees, fluency in the Finnish language is not as essential for understanding as in other subjects.

Self-responsibility and independence were, they noted, some of the values that most of them acquired from their school and, especially, their university education. When asked about what they learned during their time as students, they mentioned that learning had to be more independent, and that they had to be more responsible for their own academic affairs. These were seen as particularly important. They mentioned that this is a key element in the Finnish education system, each person is responsible for himself or herself. They explained it on the basis of the culture of study and work in Finnish society. They recognized this and compared it to cultures of their home country.

According to the interviews, teachers were perceived mainly as helpful and fair. The teachers taught everyone the same way to, they noted. The teachers showed the values of the society which are based on equality and are exhibited in schools every day. It is necessary to show these values continuously. These results also correspond with what Sahlberg (2011) described as the important features of the Finnish system. These include a high level of trust in teachers and principals as professionals, encouragement to try new approaches, a culture of respect, diversity and trust, and free access to educational institutions for all students (Bakalar, 2017; Sahlberg, 2012; Yigit \& Tatch, 2017) as features of an equitable society and school system. Nevertheless, two different perceptions seem to exist in the Finnish educational system. Teachers, based on the equality policy, try to help and support FGMFSs in their own way; however, it seems that this perception is not experienced in the same way by FGMFSs. As previously mentioned, FGMFSs experienced stress and pressure to work harder regarding their education. This is an important issue that should be considered by the education system to help understand how the functioning of the system is experienced and perceived by FGMFSs.

Furthermore, the results indicate that there are still too many misunderstandings about the institutions based on the background of the parents. Their experiences in their countries of origin have been very different. It is important that there is continuous communication between parents and teachers. It could be helpful if the values could be considered in a wider context and expand these values to their families, since students are not separate from their family values and culture. 
This study showed that the relationship with Finnish friends has helped FGMFSs to integrate culturally and academically, affecting their academic performance and sense of belonging. The way in which friendship with Finnish students and classmates within the educational system has made them more self-confident helps them to expand their knowledge of the best ways of thinking, studying, and working. They also stressed the importance of personal responsibility and independence during their university studies. They learned this on the one hand from friends and colleagues, but also from the teaching methods used in schools and colleges.

However, the study results indicated that finding friends and making friends abroad as a child or as a teenager can be associated with many difficulties. Often, there is a lack of access to certain networks, social capital as Bourdieu (1986) described it, and sometimes the knowledge is missing about the appropriate behaviors needed to make friends. A lack of language skills is often another obstacle to making friends quickly and easily. Explanations for the difficulties of making friends were often linked to the behavior of the Finnish society. Finns, according to some participants, are cautious and self-centered. Furthermore, different values regarding behavior, use of alcohol, or relationships were noted as not consistent with the culture of the host country for many migrants. According to these findings, there are clear differences in these values between cultures from the Middle East and Northern Europe. The study also showed that there are different meanings of friendship among immigrants (collectivist societies versus individualistic societies). But, the difficulties with friendship can also be explained by one's self-perception as a foreigner. This was described as an obstacle to greater interaction with Finnish students. On the other hand, those who had made friends described this as particularly valuable. Others, who had made few or no friends, found this burdensome and would very much have liked to make friends and participate more in the life of society. All of the participants pointed to the importance of friendship and social relations. For those who had close relationships with Finns, they improved their social capital, which helped them to improve their cultural and social integration at university and in everyday life. The data also showed that this increased their self-efficacy and motivation to continue their studies and to overcome barriers, challenges, and social patterns that emerge, especially in relation to language and the culture of study and work.

It is noticeable that this study found no remarkable differences in the perceptions and experiences of FGMFS with different cultural backgrounds and different nationalities in relation to the three main issues raised. The main categories of family value, institutional value and friendship (interpersonal relationship) emerged from all fifteen interviews. There are similarities and differences in their perceptions and experiences, but they cannot be traced back to their different nationalities and ethnicities. Participants from the Middle East as well as from Africa, Vietnam and Russia, all drew attention to the importance of friendship and networking, of learning the Finnish language with more focus on academic writing, emotional encouragement by their parents, of belief in their abilities and of hard work in achieving higher education and its goals. The importance of the role of teachers and values in educational institutions in achieving and successfully continuing higher education as equally emphasized. The main differences emerging between the participants were related to gender, which will be discussed in the next study of the doctoral thesis.

\section{Conclusion}

All three categories described here, family values, institutional values, and friendship, provided insightful answers to the research question of what a FGMFS perceives and experiences on the way to, in transition, and at university and helps to better understanding of what makes these students successful. The connecting element between all these categories is openness. These connections can therefore be created through openness and openmindedness. This makes it possible to learn and experience new things.

Families who migrate need to be open to the new circumstances, open to contact with schools, and open to questioning and talking with teachers. Basic values in families, such as success and achievement, are used to take education seriously and to engage in these ways. Encouragement and motivation are essential characteristics for success. The family can open the doors for their children to make friends in the host society and vice versa, and thus improve interpersonal relationships.

The institution must be open to the migrants who come from different cultures and backgrounds. Institutions can support families and friendships and their values by organizing more interaction with families and activities that promote interaction and interpersonal relationships among students. It is also important for institutions that parents learn more about the education system. They should also learn more about the values underlying the institutions, such as justice, equality, trust, responsibility and respect. This, in turn, can later foster friendships between Finns and students with migrant backgrounds and, thus, increase integration. Promoting friendship in institutions will improve academic performance and success, while insuring the social integration of migrant students.

Furthermore, making close friendships does not seem easy for FGMFSs, who do not immigrate to the host country as a child, but this could also be improved through more intercultural awareness among families on both sides. Society must be open to new fellow citizens, and of course, future fellow citizens must also be open to the new society. This was confirmed by the interviewees as an important issue. In order to also support other students with migrant backgrounds on this journey, so that social patterns (opinions, habits, attitudes) can be 
adapted and they successfully complete their studies at the university, the aspect of openness must be taken into account. Openness connects the categories with each other. To achieve this, the following points should be considered: 1. Strengthening parents (education and awareness) to support their children and see education as an attainable key to success for participation and access to society. The support could include their efforts on own education as well and particularly in learning the Finnish language; 2. Continuing efforts to promote and train the intercultural competence of teachers to learn more about the cultural differences of pupils; 3 . Continuous persistence of institutional values such as equality and equity; 4. Recognition and further strengthening of the important value of schools and universities as educational institutions; and 5. Promoting various strategies and activities within and outside institutions where children and young people can make friends and connect with society. However, the central focus must always be on emphasizing the equality of all and ensuring that these principles and values are openly implemented, lived, and respected.

\section{Disclosure Statement}

The author declares that she has no relevant or material financial interests that relate to the research described in this paper".

\section{Biographical Note}

The author is studying at $\mathrm{PhD}$ level and this study is a part of her $\mathrm{PhD}$ thesis. She has interest in migration and education studies. The multicultural and teaching background of the author has raised the interest in cultural and social perspective of education and educational institutions.

\section{References}

Abdul Rahim, A. H., \& Azman, N. (2010). Educational aspirations among first-generation students and their parental influence towards pursuing tertiary education. Procedia-Social and Behavioral Sciences, 7, 414418.

Aldiabat, K. M., \& Le Navenec, C. (2018). Data saturation: The mysterious step in grounded theory method. The Qualitative Report, 23(1), 245-261. Retrieved from https://nsuworks.nova.edu/tqr/vol23/iss1/18

Bakalar, B. (2017). Understanding the whole student: holistic multicultural education [Book Review]. Journal of Ethnic and Cultural Studies, 4(2), 96-98.

Bauer, E. (2016). Practicing kindship care: Children as language brokers in migrant families. Childhood, 23(1), 22-36. doi:10.1177/0907568215574917

Baum, S., \& Flores, S. T. (2011). Higher education and children in immigrant families. Journal of the Future of Children, 21(1), 171-193.

Bourdieu, P. (1984). Distinction: A social critique of the judgement of taste. Cambridge: Harvard University Press.

Bourdieu. P. (1986). The forms of capital. In J. G. Richardson (Ed.), Handbook of theory and research for the sociology of education (pp. 241-258). New York: Greenwood Publishing Group.

Buchanan, D., Boddy, D., \& McCalman, J. (1988). Getting in, getting on, getting out and getting back. In A. Bryman (Ed.), Doing research in organisations (pp. 53-67). Routledge: London.

Ceja, M. A. (2001). Applying, choosing, and enrolling in higher education: Understanding the college choice process of first-generation Chicana students (Unpublished doctoral dissertation). University of California, Los Angeles.

Chen, X. (2005). First-generation students in postsecondary education: A look at their college transcripts. U.S. Government Printing Office, U.S. Department of Education, National Center for Education Statistics, Washington, DC.

Choy, S. P. (2001). Students whose parents did not go to college. Washington: National Center for Education Statistics.

Coleman, J. S. (1988). Social capital in the creation of human capital. American Journal of Sociology, 94, S95S120.

Devine, D. (2009). Mobilising capitals? Migrant children's negotiation of their everyday lives in school. British Journal of Sociology of Education, 30 (5), 521-535. doi:10.1080/ 01425690903101023

Dooley, M. A., Payne, A., \& Robb, A. (2009). University participation and income differences: An analysis of application by Ontario secondary school students. Toronto: Higher Education Quality Council of Ontario.

Dumais, S. A., \& Aaryn, W. (2010). Cultural capital and first-generation college success. Poetics, 38, $245-265$.

Ecklund, K. (2013). First generation social and ethnic minority students in Christian universities: Student recommendations for successful support of diverse students. Christian Higher Education Journal, 12(3), 159-180.

Ersoy, E., \& Uysal, R. (2018). Opinions of School Psychological Counselors on Giftedness and Gifted Students' Education. American Journal of Qualitative Research, 2(2), 120-142. 
Fathi, M. (2018). Becoming a woman doctor in Iran: The formation of classed and gendered selves. Gender and Education, 30(1), 59-73.

Glaser, B. G., \& Strauss, A. L. (1967). The discovery of grounded theory: Strategies for qualitative research. New Brunswick (U.S.A.): Aldine Transaction. Retrieved from http://www.sxf.uevora.pt/wpcontent/uploads/2013/03/Glaser_1967.pdf

Holton, J. A., \& Walsh, I. (2017). Classic grounded theory. London: Sage Publications.

Horn, L., \& Nunez, A. M. (2000). Mapping the road to college: First-generation students' math track, planning strategies, and context of support. Washington: National Center of Education Statistics.

Ishitani, T. T. (2003). A longitudinal approach to assessing attrition behavior among first-generation students: Time-varying effects of pre-college characteristics. Research in Higher Education, 4(4). 433-449.

Mäkinen, M. (2013). Towards community oriented curriculum in Finnish literacy education. European Journal of Teacher Education, 36(1), 97-112. doi:10.1080/02619768.2012.696193

Malinen, O. P., Väisänen, P., \& Savolainen, H. (2012). Teacher education in Finland: A review of a national effort for preparing teachers for the future. The Curriculum Journal, 23(4), 567-584. doi:10.1080/09585176.2012.731011

Mangez, E., \& Hilgers, M. (2012). The field of knowledge and the policy field in education: PISA and the production of knowledge for policy. European Educational Research Journal, 11(2), 189-205.

Márque, J., Peña, C., Jones, L., Orange, A., \& Simieou, F. (2018). Academic success and resiliency factors: A case study of unaccompanied immigrant children. American Journal of Qualitative Research, 2(1), 162181.

Nunez, A. M., \& Cuccaro-Alamin, S. (1998). First-generation students: Undergraduates whose parents never enrolled in postsecondary education (NCES 98-082). U.S.

OECD. (2004). Learning for tomorrow's world. First results from PISA 2003. Retrieved from http://www.oecd.org/education/school/programmeforinternationalstudentassessmentpisa/34002216.pdf

OECD. (2010). PISA 2009 Results: Executive summary. OECD. Retrieved from https://www.oecd.org/pisa/pisaproducts/46619703.pdf

OECD/EU (2018), Settling In 2018: Indicators of Immigrant Integration, OECD Publishing, Paris/European Union, Brussels. https://doi.org/10.1787/9789264307216-en

Padilla-Walker, L. M. (2008). "My mom makes me so angry!" Adolescent perceptions of mother-child interactions as correlates of adolescent emotions. Social Development, 17(2), 306-325.

Quinn, D. E., Cornelius-White, J., MacGregor, C., \& Uribe-Zarain, X. (2019). The success of first-generation college students in a trio student support services program: Application of the theory of margin. Critical Questions in Education, 10(1), 44-64.

Rupsiene, L., \& Pranskuniene, R. (2010). The variety of grounded theory: Different versions of the same method or different methods? Socialiniai Mokslai, 4(70), 7-20.

Saenz, V. S., Hurtado, S., Barrera, D., Wolf, D., \& Yeung, F. (2007). First in my family: A profile of firstgeneration college students at four-year institutions since 1971. Los Angeles: Cooperative Institutional Research Program, Higher Education Research Institute, University of California.

Sahlberg, P. (2011). The fourth way of Finland. Journal of Education Change, 12(2), 173-185.

Sahlberg, P. (2012). Quality and equity in Finish schools. School Administrator, 69(8), 27-30.

Schwartz, S. H. (1992). Universals in the content and structure of values: Theoretical advances and empirical tests in 20 countries. In M. P. Zanna (Ed.), Advances in experimental social psychology, 25, 1- 65. San Diego, CA: Academic Press.

Schwartz, S.H. (2014). Functional theories of human values: Comment on Gouveia, Milfont, and Guerra. Personality and Individual Differences, 68, 247-249.

Selamat, N. H., Taib, F., Hashim, I. H. M., Mohd-Zaharim, N., \& Karupiah, P. (2013). A profile of first-generation and non-first-generation first year students: A case study of Universiti Sains Malaysia. Australian Journal of Basic and Applied Sciences, 7(8), 386-390.

Statistics Finland. (2018, October 30). Net immigration lower than in the previous year in 2017. Retrieved from https://www.stat.fi/til/muutl/2017/muutl_2017_2018-10-30_tie_001_en.html.

Stephens, N. M, Townsend, S. S. M., Markus, H. R., \& Phillips, L. T. (2012). A cultural mismatch: Independent cultural norms produce greater increases in cortisol and more negative emotions among first-generation college students. Journal of Experimental Social Psychology, 48, 1089-1393.

Strauss, A. \& Corbin, J. (1994). Grounded theory methodology - An overview. In K. D. Norman \& , S. L.Y. Vannaeds (Eds.), Handbook of qualitative research (pp. 22-23). Thousand Oaks: Sage Publications.

Terenzini, P. T., Cabrera, A., \& Bernal, E. (2001). Swimming against the tide: The poor in American higher education. Princeton, NJ: College Board.

Thomas, L., \& Quinn, J. (2007). First generation entry into higher education: An international study. Maidenhead: Open University Press. 
Weller, S. C., Vickers, B., Bernard, H. R., Blackburn, A. M., Borgatti, S., Gravlee, C. C., \& Johnson, J. C. (2018). Open-ended interview questions and saturation. PLoS One, 13(6): 00198606. doi:10.1371/journal.pone.0198606

Williams, N. (2009). Education, gender and migration in the context of social change. Social Science Research, $38,883-896$.

Yigit, I. H., \& Tatch, A. (2017). Syrian refugees and Americans: Perceptions, attitudes and insights. American Journal of Qualitative Research, 1(1), 13-31. 